\title{
APPLICATION OF INDUSTRIAL COMPUTER TOMOGRAPHY TO DETERMINE WOOD POROSITY
}

\author{
Eva BURANSKÁ ${ }^{1}$, Peter RANTUCH ${ }^{1}$, \\ Ivan BURANSKÝ ${ }^{2}$, Alexandra KUCMANOVÁ ${ }^{1}$ \\ ${ }^{1}$ SLOVAK UNIVERSITY OF TECHNOLOGY IN BRATISLAVA, \\ FACULTY OF MATERIALS SCIENCE AND TECHNOLOGY IN TRNAVA, \\ INSTITUTE OF INTEGRATED SAFETY \\ Ulica JÁNA BOTTU 2781/25, 91724 TRNAVA, SLOVAK REPUBliC \\ ${ }^{2}$ SLOVAK UNIVERSITY OF TECHNOLOGY IN BRATISLAVA, \\ FACULTY OF MATERIALS SCIENCE AND TECHNOLOGY IN TRNAVA, \\ INSTITUTE OF PRODUCTION TECHNOLOGIES \\ UliCA JÁNA BotTu 2781/25, 91724 TRNAVA, SLOVAK REPUBLIC \\ e-mail: eva.buranska@stuba.sk,peter.rantuch@stuba.sk, ivan.buransky@stuba.sk, \\ alexandra.kucmanova@stuba.sk \\ Received 11 May 2021, Accepted 23 July 2021, Published 24 November 2021
}

\begin{abstract}
The main objective of this research was to analyse the limitations of iCT - industrial computer tomography for measuring the wood pores characteristics as a new non-destructive method which is primarily intended to measure and inspect complete components primarily made of plastics or light metal. The subject matter of this paper are wood samples of paulownia (Paulownia tomentosa) and ash (Fraxinus excelsior) before and after thermal treatment. Porosity, pore volume and distribution of pores on the wood samples before and after the heat treatment were measured by iCT Metrotom 1500. The total porosity of the samples before thermal treatment was $5.28 \%$ (paulownia) and $14.90 \%$ (ash), while after thermal treatment, porosity increased to $9.50 \%$ (paulownia) and to $30.78 \%$ (ash). Changes in the porosity of the samples before and after heat treatment show an increase in porosity of $3.87 \%$ (paulownia) and $15.88 \%$ (ash).
\end{abstract}

\section{Keywords}

Computer tomography, fire prevention, porosity, wood, X-ray

\section{INTRODUCTION}

The wood porosity is a dominant impact factor in air permeability, impregnation rate and polymer retention [1], [2], [3]. 
Within all construction materials, wood has the best weight-to-load capacity ratio, which makes it possible to implement it in wooden structures in hard-to-access areas. The material is used in the exterior as well as the interior of wooden structures. The main disadvantage of the material is its ignitability; therefore, much attention is paid to increasing its fire protection properties [4], [5].

Computed microtomography is a non-invasive and non-destructive essential tool for morphological and topological studies of internal structures of different materials allowing 3D visualizations.

Currently, many studies focusing on the industrial applications using $\mu \mathrm{CT}$ as a tool are being conducted. In all applications, $\mu \mathrm{CT}$ proved to be an adequate technique for the characterization of different materials, allowing accurate and reliable qualitative and quantitative assessments [6]. Although iCT (industrial tomography) is mainly used to measure and control components in the automotive or aerospace industries, applications in biomedicine are common and CT applications are also aimed at analysing the porosity or density of natural materials (stone, wood, composites).

Previous studies reported the applications of $\mu \mathrm{CT}$ to study the dendrochronology of wood and to identify wood species [7], [8], [1]. The authors of [9] examined the porosity and microstructure characterization of composite materials reinforced with recycled fibres. The volume of pores was distributed between the constituent composite materials, and then statistically analysed. [10] used CT for measuring the wood density as an indicator of wood quality; however, in the context of global change, it is increasingly used for the biomass and carbon storage estimations.

$\mathrm{X}$-ray tomography uses the ability of X-ray radiation to penetrate objects. On the way through an object, part of the impinging radiation is absorbed. The amount of attenuation is determined by the length travelled in the absorbing material, by the material composition and its density (i.e. attenuation coefficient $\mathrm{m}$ ) and by the energy of the X-rays [11]. The longer the radiographic length of the object, the less radiation escapes from the opposite side. The absorption also depends on the material [12]. There are still some problems which need to be solved because scanning accuracy depends, among other things, on the material of parts. For example, density of metal parts is high, and their scanning leads many times to failure [13].

The analysis of images provided by $\mu \mathrm{CT}$ allowed the quantitative assessment of scaffold void fraction and accessible void fractions at the increasing connection sizes, and computerassisted analysis of $\mu \mathrm{CT}$ images exhibited a potential for the quantitative analysis of porous scaffold interconnectivity [8].

In order to use tomography on an object, several hundred two-dimensional radiographic images are made in sequence, with the measured object in various rotated positions. The object is located on a rotating table for this purpose, which is gradually rotated step by step. The threedimensional information about the measured object contained in this series of images is extracted using a suitable mathematical process and is made available as a "voxel image". Each voxel (volume pixel) embodies the X-ray absorption by the measured object for a defined location in the measured volume. Similar to two-dimensional image processing, the actual measured points are calculated from the voxel data using a suitable threshold process [12].

The measurement target (sample) is positioned between the X-ray generator and the X-ray detector, as shown in Figure 1. X-ray data is collected from every angle by rotating the sample by 360 degrees, and then tomographic images (CT images) are calculated. 


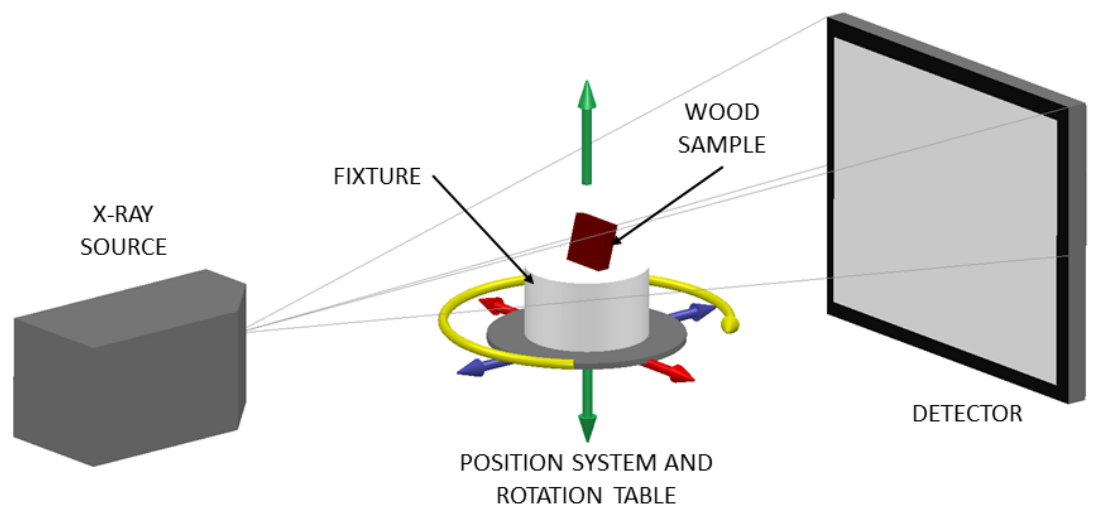

Fig. 1 Schematic representation of industrial tomography

The main objective of this research was to analyse the limitations of iCT - industrial computer tomography to measure wood pores characteristics, as a new non-destructive method which is primarily intended for measuring and inspecting complete components primarily made of plastics or light metal.

\section{MATERIALS AND METHODS}

\section{Materials}

Paulownia (Paulownia tomentosa) and ash (Fraxinus excelsior) were dried in an oven at $103 \pm 2{ }^{\circ} \mathrm{C}$ for 24 hours to oven dry moisture content. The porosity and other parameters in Table 4 were measured before and after heat treatment. Both wood samples were heat treated at $180{ }^{\circ} \mathrm{C}$ for 4 hours.

Table 1 Wood sample data

\begin{tabular}{|l|c|c|c|}
\hline & Paulownia & Ash & \\
\hline Weight before thermal treatment $\left(\mathrm{M}_{0}\right)$ & 50.55 & 135.07 & $\mathrm{~g}$ \\
\hline Weight after thermal treatment $\left(\mathrm{M}_{1}\right)$ & 49.01 & 131.12 & $\mathrm{~g}$ \\
\hline Total volume before thermal treatment $\left(\mathrm{V}_{0}\right)$ & 181.03 & 188.98 & $\mathrm{~cm}^{3}$ \\
\hline Total volume after thermal treatment $\left(\mathrm{V}_{1}\right)$ & 178.18 & 179.07 & $\mathrm{~cm}^{3}$ \\
\hline Density before thermal treatment $\left(\mathrm{D}_{0}\right)$ & 0.2792 & 0.7147 & $\mathrm{~g} / \mathrm{cm}^{3}$ \\
\hline Density after thermal treatment $\left(\mathrm{D}_{1}\right)$ & 0.2707 & 0.6939 & $\mathrm{~g} / \mathrm{cm}^{3}$ \\
\hline
\end{tabular}

The oven-dry density ( $\left.\mathrm{D}_{0}\right)$ [19] and (D1) was determined by using the following equation:

$$
D_{0.1}=M_{0.1} / V_{0.1}\left(\mathrm{~g} / \mathrm{cm}^{3}\right) \text {, }
$$

where $M_{0}$ is the oven-dry weight of the samples $(\mathrm{g})$ and $\mathrm{V}_{0}$ is the volume of the samples $\left(\mathrm{cm}^{3}\right)$ before thermal treatment and $\mathrm{M}_{1}$ is the oven-dry weight of the samples $(\mathrm{g})$ and $\mathrm{V}_{1}$ is the volume of the samples $\left(\mathrm{cm}^{3}\right)$ after thermal treatment. Total sample volume $\left(\mathrm{V}_{0}\right.$ and $\left.\mathrm{V}_{1}\right)$ was obtained by the CT scan analysis using function Porosity/Inclusion analysis (VGDefx/Only Threshold) in VGStudio MAX 3.0.

Paulownia is an economically important genus in the family Scrophulariacease, with nine species of the adaptable and fast-growing timber trees [14], [15]. Paulownia is receiving increasing attention as being suitable for use as a short-rotation woody crop in many parts of the world. Paulownia wood is marketed primarily for special solid wood products such as 
oriented strand board and, veneer, as well as for pulp to produce fine papers and timber production. Most species of paulownia are extremely fast growing, and can be harvested in 15 years for valuable timber [16]. Low quality lumber can easily be produced from the 6-7-year-old trees. The wood of paulownia is soft, lightweight, ring-porous, straight-grained, and mostly knot-free wood with a satiny lustre. The average reported density of the wood is from $0.35 \mathrm{~g} / \mathrm{cm}^{3}$ [16] to $0,29 \mathrm{~g} / \mathrm{cm}^{3}$ [17].

The slender ash tree (Fraxinus excelsior) is a deciduous tree from the olive family Oleaceae. It is circular-porous. Ash is ring-porous hardwoods with similar oven-dry wood density. It is one of the most flexible and toughest woods. It is well processed and surface treated. Ash wood is under-represented in our country, but it still belongs to industrially important woody plants. The average reported density of the wood is $0.6773 \mathrm{~g} / \mathrm{cm}^{3}$ [18].

\section{Methods}

In general, the percentage of cell wall and porosity was calculated from the following equations:

$$
\begin{gathered}
V_{c}=D_{0} / D_{c} \times 100(\%) \\
V_{H}=100-V_{c}(\%),
\end{gathered}
$$

where $\mathrm{V}_{\mathrm{c}}$ is the percentage of the cell wall $(\%), \mathrm{D}_{0}$ is oven-dry density $(\mathrm{g} / \mathrm{cm} 3), \mathrm{D}_{\mathrm{c}}$ is oven-dry density of the cell wall $\left(1.5 \mathrm{~g} / \mathrm{cm}^{3}\right)$ and $\mathrm{V}_{\mathrm{H}}$ is the percentage of porosity (\%) [19].

\section{$X$-ray industrial computed tomography scanning (iCT)}

CT device - METROTOM 1500 of Carl Zeiss Company. It is an industrial computed tomography system for measuring and inspecting complete components primarily made of plastics or light metal. Specification of data acquisition is available in Table 2. VGStudio Max 3.0 Software was used to obtain the results (pore volume etc.).

These settings of data showed in Table 2 directly affect the size of the voxel, i.e. the resolution of the resulting point cloud. If the component is closer to the radiation source, i.e. further from the detector, the image of the component projected onto the detector is larger and the actual dimensional voxel is smaller. For small parts, it is possible to obtain a resolution below $10 \mu \mathrm{m}$. In our case, we reached a voxel size of $66.47 \mu \mathrm{m}$ which affected further pore analysis (Fig.2.).

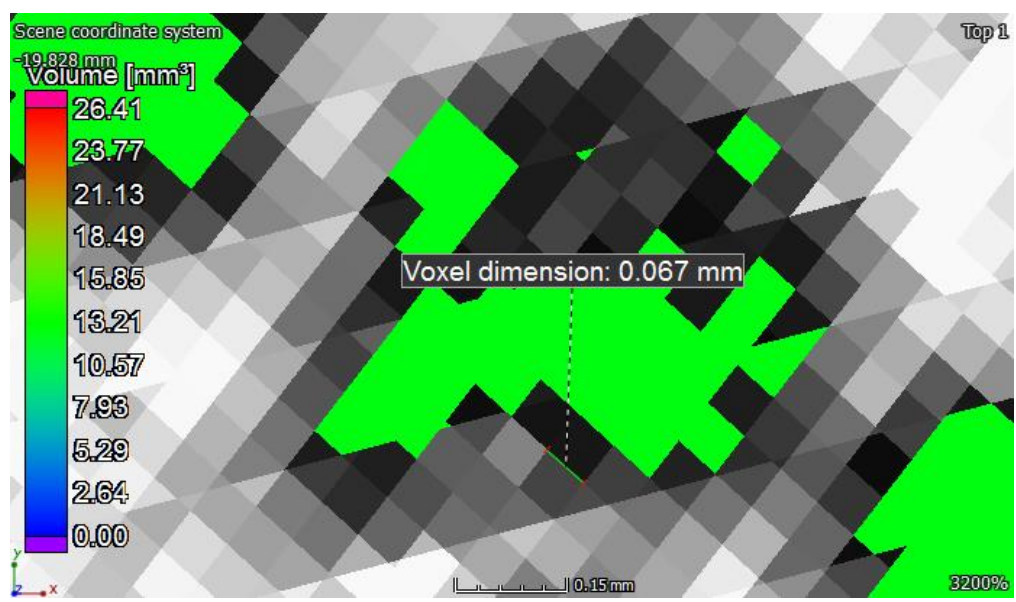

Fig. 2 Voxel dimension 
Table 2 Data acquisition

\begin{tabular}{|l|c|c|}
\hline Voltage & 150 & $\mathrm{~kW}$ \\
\hline Current & 400 & $\mu \mathrm{A}$ \\
\hline Integration time & 1000 & $\mathrm{~ms}$ \\
\hline Gain & 16 & - \\
\hline Averaging & off & - \\
\hline Binning & $1 \mathrm{x} 1$ & - \\
\hline Voxel size & 66,47 & $\mu \mathrm{m}$ \\
\hline
\end{tabular}

The analysis of pores and inclusions can be performed on the sample or its part bounded by the surface. This analysis automatically detects and visualizes pores or inclusions (defects) in the material bounded by the surface. The volume, position, size and surface are determined for each individual defect detected. According to the volume, the objects are colour-coded. Defect size statistics, total porosity percentage and defect volume histogram can be added to the outputs. This information indicates the quality and value of the material. Because the procedure and conditions of porosity analysis may be different with respect to the data obtained by CT scanning and the need for analysis, we present individual steps of the procedure and conditions of pores analysis in Table 3. This is important for the possibility of reproducing the measurement.

The steps of obtaining the data about samples porosity were followed [9]:

1. Importing the CT data of parts from Metrotom OS to VGStudio MAX 3.0.

2. Used function "Surface determination" of each CT parts.

3. Creating ROI (Region of Interest) from surface.

4. Using the function of "Selection modes - Erode/dilate" and changing mode to Opening/Closing. We used the function because all pores were open, and after that the part is closed.

5. Changing the surface determination in advanced mode - the starting contour was changed to ROI from surface.

6. Preparing the part for pores analysis.

7. Using the Porosity/Inclusion analysis function (VGDefx/Only Threshold).

8. Preparing a colour deviation map that is common for all results of the CT scanned parts.

Table 3 Properties of porosity/inclusion analysis (VGDefX/Only Threshold)

\begin{tabular}{|l|c|c|}
\hline Deviation factor & -0.20 & \\
\hline Noise reduction & high & \\
\hline Probability criterion & size & \\
\hline Analysis area & from surface (as seen) & \\
\hline Surface sealing & on & \\
\hline Probability threshold & 1.00 & \\
\hline Min. volume size & 0.00 & $\mathrm{~mm}^{3}$ \\
\hline Max. volume size & 5000.00 & $\mathrm{~mm}^{3}$ \\
\hline
\end{tabular}




\section{RESULTS AND DISCUSSION}

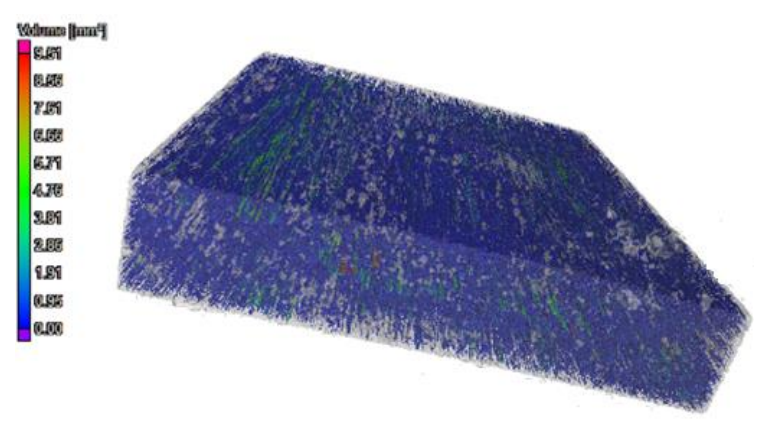

a) before thermal treatment

(tolerance of colour deviation map from 0 to $9.51 \mathrm{~mm}^{3}$ )

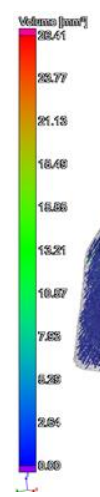

b) after thermal treatment

(tolerance of colour deviation map from 0 to $26.41 \mathrm{~mm}^{3}$ )

Fig. 3 Porosity of paulownia (Paulownia tomentosa)

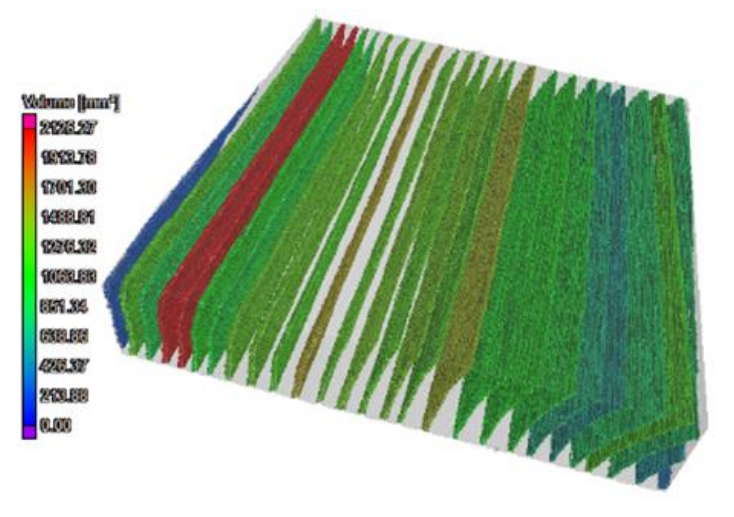

a) before thermal treatment (tolerance of colour deviation map from 0 to $2126.27 \mathrm{~mm}^{3}$ )
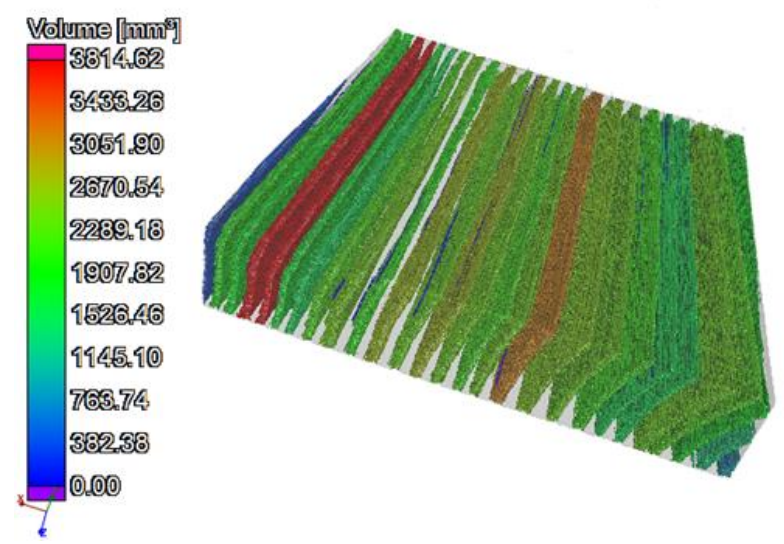

b) after thermal treatment (tolerance of colour deviation map from 0 to $3814.62 \mathrm{~mm}^{3}$ )

Fig.4 Porosity of ash (Fraxinus excelsior)

\section{The porosity, pore size, pore volume and distribution detected by iCT}

Pore distribution in samples is showed in colour maps in Fig. 3 and Fig. 4. Wood is a heterogeneous material, diverse at the level of macro and microstructure; therefore, the pore distribution is also different.

In paulownia (Fig. 3), the pores are narrow (acicular), distributed throughout the volume of the wood. In ash (Fig. 4), the pores are circular placed in annual rings. The results derived from the porosity measurements of the samples are shown in Table 4 . The total porosity defect volume ratio for paulownia before heat treatment was $5.28 \%$, and that for ash was $14.90 \%$. The porosity defect volume ratio increased after heat treatment. The paulownia porosity defect volume ratio increased by $3.87 \%$ and ash by $15.88 \%$ after heat treatment. From the colour map and statistics, it is possible to evaluate the number of pores, the total volume of pores, the distribution (pore position in the $\mathrm{X}, \mathrm{Y}$ and $\mathrm{Z}$ coordinate systems) and volume or surface of individual pores.

The ash was specific by the distribution of pores according to the annual rings, which corresponded to the information about the volume of individual pores. The number of pores in 
ash was much smaller, but the pore volume was high. By comparing the wood samples based on the colour map, it can be stated that these data depend on the structure and type of wood. The porosity characteristics as well as the distribution and volume of pores represent the information that can be necessary for further modifications of the materials in terms of fire technical characteristics.

\begin{tabular}{|l|c|c|c|c|}
\hline Table 4 Porosity results & $\begin{array}{c}\text { Paulownia } \\
\text { before } \\
\text { thermal } \\
\text { treatment }\end{array}$ & $\begin{array}{c}\text { Ash } \\
\text { before thermal } \\
\text { treatment }\end{array}$ & $\begin{array}{c}\text { Paulownia } \\
\text { after thermal } \\
\text { treatment }\end{array}$ & $\begin{array}{c}\text { Ash } \\
\text { after thermal } \\
\text { treatment }\end{array}$ \\
\hline Number of defects (-) & 125000 & 28 & 94716 & 64 \\
\hline Pore volume range $\left(\mathrm{mm}^{3}\right)$ & $0.01-9.51$ & $1.39-2126.27$ & $0,01-26,41$ & $1.02-3814.62$ \\
\hline Material volume $\left(\mathrm{mm}^{3}\right)$ & 171468.63 & 160826.59 & 161870.00 & 123949.38 \\
\hline Total pore volume $\left(\mathrm{mm}^{3}\right)$ & 9559.23 & 28153.40 & 16305.80 & 55118.51 \\
\hline Porosity - defect volume ratio $(\%)$ & $\mathbf{5 . 2 8}$ & $\mathbf{1 4 . 9 0}$ & $\mathbf{9 . 1 5}$ & $\mathbf{3 0 . 7 8}$ \\
\hline
\end{tabular}

The measured values of the paulownia porosity in comparison with the reported average values [17], [19] are lower, which could be influenced by the parameters of the scanning process, where we obtained a voxel of $66.37 \mu \mathrm{m}$. Owing to the needle shape and low pore volume as well as the fact that the voxel was too large, not all pores in the sample could be identified. The resolution for scanning could be improved (e.g. smaller sample, scanning only a part of the sample, using the possibility of combining scans, etc.)

The variations in the wood properties of the same species were due to different factors, such as growth conditions and ecological factors. In particular, exposure, altitude, soil and climate conditions can affect wood properties. Sample size and properties (e.g. ring orientation), and the test procedure can also affect the test results [19].

\section{CONCLUSION}

This paper deals with the application of an industrial computed tomography in evaluating porosity of natural materials, such as wood. Porosity analysis of wood is important for the further application of these materials, for example in construction. Two types of wood were examined, namely paulownia and ash, especially with regard to the expected differences in the amount, spacing, shape and total pore volume of the wood.

For iCT measurements, the pore distribution trends of two samples were different. In paulownia, the pore volume ranged from $0.01-9.51 \mathrm{~mm}^{3}$ by 125000 defects; on the other hand, the pore volume of ash ranged from $1.39-2126.27 \mathrm{~mm}^{3}$ by 28 defects before thermal treatment. Although paulownia contained a larger number of pores, their volume and shape were smaller.

The porosity characteristics as well as the distribution, shape and volume of pores in the wood form a precondition for the use of these materials for further modifications in terms of fire technical characteristics. Based on the results of measurements, it can be stated that an industrial computed tomography can be used to evaluate the porosity of wood, although several problems should be overcome in data processing, e.g. optimizing the scanning process to reduce the voxel value to the lowest possible value, which will be the subject of further research.

\section{Acknowledgement}

The article was written with the support of the KEGA 020STU-4/2021 Project. 


\section{References}

[1] PENG, L. M., WANG, D., FU, F., SONG, B. Q. 2015. Analysis of wood pore characteristics with mercury intrusion porosimetry and x-ray micro - computed tomography. Wood Research, 60(7), 857-864. ISSN 13364561.

[2] SULEIMAN, B. M., LARFELDT, J., LECKNER, B., GUSTAVSSON, M. 1999. Thermal conductivity and diffusivity of concrete. Journal of the Franklin Institute, 193(1), 120. ISSN 00160032.

[3] DING, W. D., KOUBAA, A., CHAAlA, A., BELEM, T., KRAUSE, C. 2008. Relationship between wood porosity, wood density and methyl methacrylate impregnation rate. Wood Material Science and Engineering, 3 (1-2), 62-70. ISSN 17480272

[4] OSVALDOVÁ, L. M., GAFF, M. 2017. Retardation effect on thermally-modified spruce wood. WIT Transactions on Ecology and the Environment, 226(1), 537-546. ISSN 17433541

[5] AKKUS, M., BAHCEGUL, E., OZKAN, N., BAKIR, U. 2014. Post-extrusion heat-treatment as a facile method to enhance the mechanical properties of extruded xylan-based polymeric materials. RSC Advance, 4(107), 62295-62300. ISSN 2046-2069

[6] MACHADO,A. S., SILVA, A. S., De ARAÚJO,O. O., DE OlIVEIRA, D. F., LOPES, R. T. 2020. Industrial applications of computed microtomography ( microCT ) technique. In: 10th Conference on Industrial Computed Tomography : Wels, Austria (iCT 2020), pp.1-6.

[7] MIZUNO, S., TORIZU, R., SUGIYAMA, J. 2010. Wood identification of a wooden mask using synchrotron X-ray microtomography. Journal of Archaeological Science, 37 (11), 2842-2845. ISSN 10959238.

[8] MOORE, M. J., JABBARI, E., RITMAN, E. L., LU, L., CURRIER, B. L., WINDEBANK, A., J., YASZEMSKI, M. J. 2004. Quantitative analysis of interconnectivity of porous biodegradable scaffolds with micro-computed tomography. Journal of Biomedical Materials Research - Part A, 71(2), 258-267. ISSN 00219304.

[9] SABAU, E., UDROIU, R., BERE, P., BURANSKÝ, I., MIRON-BORZAN, C. Ş. 2020. A novel polymer concrete composite with GFRP waste: Applications, morphology, and porosity characterization. Applied Sciences (Switzerland), 10(6). ISSN 20763417.

[10] LONGUETAUD, F., FREYBURGER, C., MOTHE, F., CONSTANT, T., LEBAN, J. M. 2009. Measuring wood density by means of X-ray computer tomography. Annals of Forest Science, 66 (8). ISSN 12864560.

[11] KRUTH, J. P., BARTSCHER, M., CARMIGNATO, S., SCHMITT, R., DE CHIFFRE, L., WECKENMANN, A. 2011. Computed tomography for dimensional metrology, CIRP Annals Manufacturing Technology, 60(2), 821-842, ISSN 00078506.

[12] KRITIKOS, M. 2020. Effect of the voxel size on the final scan accuracy in Computed Tomography. In: International Conference on Production Research, pp. 1285-1301. ISBN 1336202000074 .

[13] KRITIKOS, M., BURANSKÝ, I., BURANSKÁ, E., MOJŽIŠ, M. 2019. Evaluation of accuracy of seamless steel tube scanning by industrial computed tomography. MATEC Web of Conferences, 229, 04009

[14] YORGUN, S., YILDIZ, D. 2015.Preparation and characterization of activated carbons from Paulownia wood by chemical activation with H3PO4. Journal of the Taiwan Institute of Chemical Engineers, 53, 122-131. ISSN 18761070.

[15] YAYCILI, O., ALIKAMANOGLU, S. 2005. The effect of magnetic field on Paulownia tissue cultures. Plant Cell, Tissue and Organ Culture, 83(1), 109-114. ISSN 01676857.

[16] KALAYCIOGLU, H., HIZIROGLU, S., DENIZ, I. 2005. Some of the properties of particleboard made from paulownia. Journal Wood Science, 51(4) 410-414. ISSN 14350211.

[17] AKYILDIZ, M. H., KOL SAHIN, H. 2010. Some technological properties and uses of paulownia (Paulownia tomentosa Steud.) wood. Journal of Environmental Biology, 31(3), 351-355. ISSN 2394-0379.

[18] GIAGLI, K., BAAR, J., FAJSTAVR, M., GRYC, V., VAVRČÍK, H. 2018. Tree-ring width and variation of wood density in fraxinus excelsior L. and Quercus robur L. growing in floodplain forests. BioResources, 13(1). 804-819. ISSN 19302126. 
[19] KIAEI, M. 2013. Technological Properties of Iranian Cultivated Paulownia Wood (Paulownia Fortunei ). Cellulose Chemistry and Technology, 47(9-10). 735-743.

\section{ORCID}

Eva Buranská

Peter Rantuch

Ivan Buranský

Alexandra Kucmanová
$0000-0002-2382-7508$

$0000-0001-5826-8323$

0000-0002-7600-9007

0000-0003-3089-7712 